\title{
Environmental impacts of war's social consequences. Case Study: Aleppo Governorate Syria
}

\author{
Kyriaki Papadimitriou ${ }^{1}$, Dimitrios Koumoulidis ${ }^{1}$, Lida Papalamprou ${ }^{2}$, Christoforos Kasimatis ${ }^{2}$, Panagiotis \\ Sparangis ${ }^{2}$, Nikolaos Katsenios ${ }^{2}$, Dimitrios Vlachakis ${ }^{3,4,5}$, Dimitris Triantakonstantis ${ }^{2}$, Aspasia Efthimiadou ${ }^{2}$ \\ 'Open University of Cyprus, Nicosia, Cyprus \\ 2Department of Soil Science, Institute of Soil and Water Resources, Hellenic Agricultural Organization “DEMETER”, Lycovrisi, Greece \\ ${ }^{3}$ Laboratory of Genetics, Department of Biotechnology, School of Applied Biology and Biotechnology, Agricultural University of \\ Athens, Greece \\ ${ }^{4}$ Lab of Molecular Endocrinology, Center of Clinical, Experimental Surgery and Translational Research, Biomedical Research \\ Foundation of the Academy of Athens, Greece \\ ${ }^{5}$ Department of Informatics, Faculty of Natural and Mathematical Sciences, King's College London, London, United Kingdom \\ Competing interests: KP none; DK none; LP none; CK none; PS none; NK none; DV none; DT none; AE none
}

\section{Abstract}

War is an anthropogenic phenomenon with devastating effects, which cause loss of human life, alongside the disastrous effects on the natural environment. The environmental impacts of armed conflicts can be either direct, arising from the act of war itself, or indirect due to the massive population displacement, infrastructure breakdown, and militarised zones. Impacts may be irreversible, affecting areas even far away from the territory of the conflict where they manifest. The environmental impacts of war create social and economic consequences that lead to greater environmental degradation by showing the interdependent relationship between the environment, society, and economy. It is imperative to address the subject in a multidisciplinary approach and implement stricter international legislation on environmental disasters during wars. This study aims to identify environmental impacts by using satellite-derived images at Aleppo Governorate, analyse them via statistics supplemented with the available information for the research region, and demonstrate the subsequent social and economic consequences by creating indices, such as the Normalised Difference Vegetation Index (NDVI), digital image composites and classified images, which record the extent of reduction of healthy vegetation and the extent of destruction at the city of Aleppo. Data from international organisations corroborated the findings, and hereinafter societal and economic effects were analysed. Using remote sensing alongside with geographic information systems can be a useful tool as it offers access to war zones where physical observations are usually impossible.

\section{Introduction}

Armed conflicts are one of the most devastating human activities, creating enormous humanitarian crises in addition to destroying the natural environment. The effects of armed conflict do not only occur during its duration but may continue to manifest for many years after its end. In most cases, the impacts of war are particularly serious, long-lasting, and irreversible. To better understand these impacts, a classification of wars into three stages: preparation, armed conflict, and post- war period, introducing the term "warfare ecology", was reported (Machlis and Hanson, 2008).

In 2017, 90,000 deaths were recorded worldwide, due to armed conflicts. Moreover, 49 active fronts were recorded in the same year (Pettersson and Eck, 2018), while most of them were in Syria. According to the Uppsala Conflict Data Program, 313,418 deaths in armed conflicts have occurred in Syria since the start of the war in 2012 (UCDP, 2018).

The ongoing war in Syria has forced 5.63 million people to immigrate from their country, according to

\section{Article history}

Received: 11 October 2020

Accepted: 17 January 2021

Published: 30 September 2021

(c) 2021 Papadimitriou et al.; the authors have retained copyright and granted the Journal right of first publication; the work has been simultaneously released under a Creative Commons Attribution Licence, which allows others to share the work, while acknowledging the original authorship and initial publication in this Journal. The full licence notice is available at http://journal.embnet.org. 
the United Nations High Commissioner for Refugees (OCHA, 2018; UNRA, 2018), while the number of internally displaced people was as high as 5.7 million until January 2017 (The World Bank, 2017b). With almost half of its population displaced, Syria is experiencing the largest forced population movement in modern history since World War II. The destruction of urban and semiurban centres and the abandonment of cultivated lands and areas which had intense human activity in the past, have disturbed the balance of the ecosystem. These disturbances have a good impact on wildlife but cannot be considered positive due to the huge disaster caused (Gaynor et al., 2016).

The importance of the environment has emerged in recent years as a major issue. The environmental impact of war has not received proper attention, even though it contributes to ecological degradation (Clark and Jorgenson, 2012). Limited publications are referring to the environmental impacts of war which mainly address specific areas (Sudan, Iraq, Vietnam, Congo), neglecting many areas that have experienced successive military conflicts, such as the Philippines or Myanmar. A particularly large number of publications are addressing the Gulf War (1991) considering the soil contamination due to the destruction of oil wells and air pollution caused by their combustion (Al Ajmi and Ud din, 2009; Khordagui and Al-Ajmi, 1993; Misak et al., 2009; Omar et al., 2009).

One of the restrictions that recognise and document the effects of war, is that the collection of on-site data in war zones involves practically impossible space-time constraints. Therefore, satellite technologies represent a useful tool for observing and recording the impact of environmental indicators in war-torn areas. With the use of Geographic Information Systems (G.I.S.), an effort is made to identify and record the environmental impacts in the Aleppo region, which has been in constant war since 2011. Moreover, this study reports the resulting socio-economic consequences which emerge from the environmental issues created by war. The aim is to create correlations between the war in Syria, and in particular in the area of the Aleppo Governorate, and its consequences on the three main pillars of sustainability (environmentsociety-economy) with particular emphasis on environmental impacts. Finally, this research highlights the devastating impacts of war in the study area, thus, showing the need to create a database for the immediate and targeted restoration of the impacts at the end of the conflict.

The ongoing war in Syria has created debris on urban and rural areas, degrading the already burdened status of the environment and its natural resources due to the debris dust. Especially, the disaster in the big urban centres is excessive, with the city of Aleppo and its region counting the largest percentage of disasters.

One of the most obvious effects of the conflict is the volume of debris created by the damage of urban centres, which poses a great risk to public health and the environment, as they contain dust and can contaminate soil and aquifers. In the city of Aleppo alone, it is estimated that there are (as of February 2017) 14.9 million tonnes of debris, and it is estimated that they require 6 years of continuous work and 26 million kilometres of transport to be completely removed (The World Bank, 2017b). In an effort to determine the economic dimension to a precise scale of urban disasters, the World Bank, in a report of the assessment of disasters in three urban areas of Syria (The World Bank, 2017a), estimates that the housing/building damages in the Aleppo region range from $\$ 6.2$ to $\$ 7.5$ million.

The loss in Gross Domestic Product (G.D.P.) since the first year of the crisis amounted to 24,098 million dollars, as the tourism sector and the manufacturing (public and private) sector showed a decrease in revenue of $90 \%$ and $76 \%$, respectively (Nasser et al., 2013). The country's public debt increased from 30\% of Gross Domestic Product in 2010 to $150 \%$ in 2015 (The World Bank, 2017b). There has been a sharp rise in domestic consumer prices with a direct impact on poor and highrisk social groups, leading three million people to poverty in the first year of the war, and by the end of 2015, six in ten people to live in extreme poverty (Nasser et al., 2013; The World Bank, 2017b).

Rural areas accounted for $75 \%$ of Syria's total area (CBS, 2004) and, before the crisis, contributed $18 \%$ to gross domestic product and $23 \%$ to exports (FAO, 2016). Given that annual precipitation in Syria counts up to $68.5 \%$ of the main source of water available for irrigation, as well as the drought that hit the region during the first decade of the new millennium (Erian, 2011), it is clear that rural areas were already facing serious problems even before the start of the war. The war has led to a reshuffle of water use, drastically reducing access to irrigation due to ongoing conflicts, population movements, damage of water transport infrastructure, and a lack of energy and agricultural inflows (Saadé-Sbeih, et al., 2016).

Additionally, the ongoing crisis in Syria has drastically changed the population distribution, due to mass and recurring immigration movements. The birth rate in the remaining population has decreased by $27 \%$, while the male life expectancy, aged 15 to 24 years, has decreased by $31 \%$, from 69.7 years in 2010 to 48.2 in 2014 (SCPR, 2016). Specifically, the percentage of young people aged 15 to 39 has dropped dramatically between the remaining population and the population moving within the country. Within Syrian governments, the degree of change in population distribution also varies. There is a significant decrease in population in governments such as Aleppo, the rural area of Damascus, Homs, but an increase in populations in Latakia and Hamah (SCPR, 2016). Statistics reflect a structural distortion of the population in terms of age.

An age group that faces many problems is children. Most of them do not go to school, and many of them are forced to work in harsh conditions to help their family survive. In the future, as the country's population grows, the number of people with low education will increase. In addition, the number of vaccinated children decreased 
from $98.9 \%$ before the crisis to $32.6 \%$ after the crisis, and especially in the government of Aleppo, the decrease reached 32.6\% (SCPR, 2016). As a result, diseases such as poliomyelitis, leishmaniasis and measles are widely spread (WHO, 2017).

\section{Materials and Methods}

\section{Study area}

Syria was considered one of the most peaceful countries in the region until the spring of 2011, when the first conflicts broke out in southern Syria in the province of Daraa, as a continuation of the so-called Arab Spring. The majority of Syria's population is Arab, except for a 9.7\% of the population which is Kurds, Armenians, and other minorities, while before the conflicts, there were almost 1.8 million refugees mainly from Iraq (Zwijnenburg and Pas, 2015). According to the Statistical Service of Syria (2010), Aleppo Governorate is the most populous governorate in Syria, with $24 \%$ of the total country's population. It is located in the northern part of the country within an area of $18,482 \mathrm{~km} 2$. According to the last census of the Statistical Service of Syria in 2004, the total population of the governorate was 4,045,166, while according to the 2014 population survey it was estimated that the population was $4,275,000.70 \%$ of the population is Sunni, however, in Aleppo, there are minorities of Christians, Armenians, Kurds, and Turkmens (SNAP, 2013).

The capital of the governorate is Aleppo city, which was the economic capital of Syria, as well as its industrial, agricultural, and commercial centre. Nevertheless, the Aleppo governorate is the poorest, especially in its rural areas where the poverty rate is twice the national average and three times the average urban population (SNAP, 2013). The governorate has a total of 22 cities, 1,476 villages and 1,312 farms. The wider area is a base for textile, chemical, mechanical and food industries. In the governorate of Aleppo, 20\% of the country's total wheat production was produced. The total arable land of Aleppo was estimated at 1.11 million hectares in 2011 (CBS, 2003 2017), equal to about 25\% of the total cultivated land in the country.

\section{Methods and Techniques}

The process of assessing the environmental impacts of armed conflict requires a multi-level view and relevant correlations. Any attempt to assess these impacts is de facto accompanied by the uncertainty of the results, due to lack of data from international and domestic organisations, which estimate that the magnitude of disaster is very difficult to be accurately captured, especially for the region of Syria.

Three stages of data collection were adopted in this study, as following:

1. Elaboration of existing international literature referring to the effects of armed conflicts, both in terms of environmental impact and socioeconomic impact.

2. Collection of statistical data of the area by the Statistical Service of Syria and international organisations, such as the World Bank and United Nations.

3. Collection and Use of Landsat8 satellite images by the United States Geological Survey (USGS). Also, the employment of higher resolution satellite imagery via Google Earth Pro.

The main source of data collection in this study is the Central Bureau of Statistics in Syria. However, due to the ongoing war situation in the region, the data collected is accurate until 2010, while for the years 2011-2017 the available data are either based on estimates or are nonexistent for some areas. Indicatively, it is reported that population data for the governorate of Aleppo do not exist for the above-mentioned period.

Part of the collected data relates to population changes, and especially deaths and immigration characteristics. In particular, the data for deaths and population movements were derived from the Uppsala Conflict Data Program of the University of Uppsala's Department of Peace and Conflict Research. Data collected for cultivated areas in the region were extracted from the World Bank, the United Nations (UN) and the Food and Agriculture Organization (FAO). To determine the magnitude of the disaster in the city of Aleppo, UNOSAT data were used, which is a program to provide humanitarian data through the processing of high-resolution satellite images, intending to use them for humanitarian aid and security, as well as for strategic, territorial and development planning in the affected areas. The images used by UNOSAT came from the satellites WorldView-1, WorldView-2, Pleiades, GeoEye-1, and QuickBird-2 and concern the period 2011-2015.

The source used to collect the satellite images was the United States Geological Survey (USGS). The Landsat8 satellite, which has two sensors, the Operational Land Imager (OLI) and Thermal Infrared Sensor (TIRS), was selected. The satellite images have undergone level one processing, which includes corrections via the Level Product Generation System (LPGS) algorithm for radiometric image correction to achieve greater absolute and relative geometric accuracy (USGS, 2016).

For the government of Aleppo, images were selected in two time periods, October 2013, and the corresponding month of 2017. The choice of month of the satellite images was not unintentional. The largest percentage of the area is covered by agricultural lands and therefore, to avoid taking images during the cultivation periods in winter and spring that could lead to false results, October was selected. Moreover, at this period the research area has low rainfall, in contrast to the above-mentioned periods where the soil is covered with crops and weeds.

The government of Aleppo is shown in two images with path 173 and 174 and row 35 . The four images 
Table 1. Details of the satellite images for 2013 and 2017.

\begin{tabular}{|l|c|c|c|c|c|c|}
\multicolumn{1}{c}{ Image ID } & PATH & ROW & DATE & QUALITY & $\begin{array}{c}\text { CLOUD } \\
\text { COVER }\end{array}$ & $\begin{array}{c}\text { CLOUD } \\
\text { COVER }\end{array}$ \\
\hline LC81730352013274LGN01 & 173 & 35 & $2013-10-01$ & 9 & 0.04 & 0.04 \\
\hline LC81740352013281LGN01 & 174 & 35 & $2013-10-08$ & 9 & 0.13 & 0.23 \\
\hline LC81730352017285LGN01 & 173 & 35 & $2017-10-12$ & 9 & 0.35 & 0.35 \\
\hline LC81740352017292LGN00 & 174 & 35 & $2017-10-19$ & 9 & 0.16 & 0.19
\end{tabular}

(two for each year) selected have quality 9 and no cloud coverage in the area of interest. Their details are given in Table 1. The projected coordinate system used is the transverse Mercator UTM projection in zone 37 and WGS84 as ellipsoidal.

Indices were created in the study area, for the dates 2013 and 2017 in order to analyse the spatial-temporal results. One of the most well-known and widespread indicators is the Normalised Difference Vegetation Index (NDVI). The index is derived from the ratio:

$$
N D V I=(N I R-\text { red }) /(N I R+\text { red })
$$

and counts values from -1 to 1 , with healthy vegetation ranging from 0.20 to 0.80 . Due to the fact that the reflected radiation in the near-infrared is much higher than in visible, and given the intense reflection due to the cellular structure of the leaves, the vegetation will be more photosynthetically active in places where the local maximum occurs. The change in the use of cultivated lands is one of the effects of war which is often investigated with the selection of NVDI index (Brown, 2010; Witmer and O'Loughlin, 2011; Muller et al., 2016).

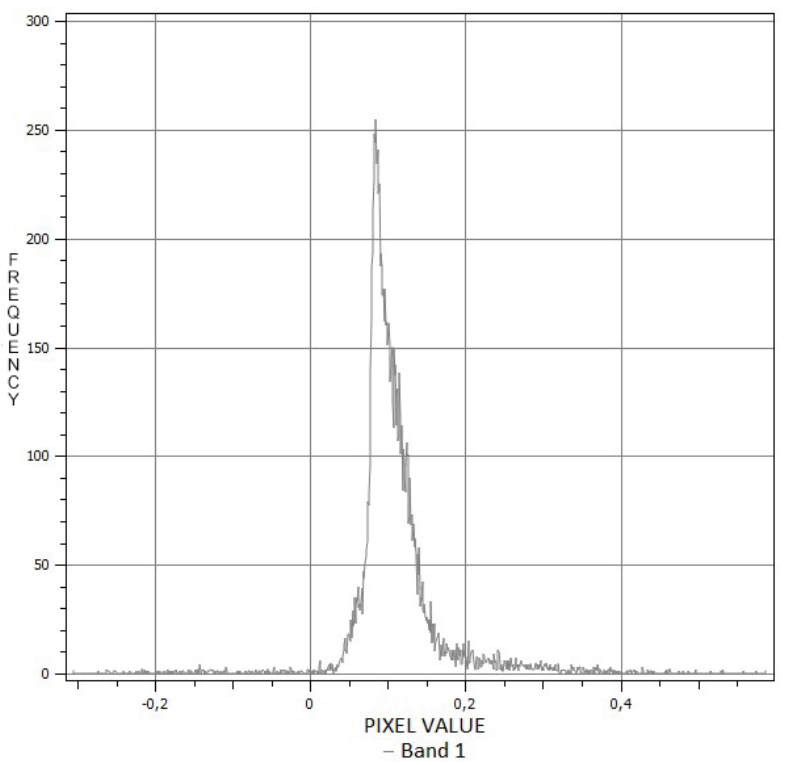

Figure 1. Histogram NDVI for 2013.
In addition, the Normalised Burn Ratio (NBR) was used as an indicator. The NBR index follows the NDVI philosophy and is mainly used to highlight burned areas. It is based on the rationale that an area with healthy vegetation has high reflectivity in the near-infrared (NIRband5) and low in the small infrared (SWIR2-Band7), while on the contrary, a burned area has low reflection in near infrared and large in small infrared. A high NBR value indicates an area with healthy vegetation, while a small value indicates a newly burned area or bare ground. The index is derived from the ratio:

$$
N B R=(N I R-S W I R 2) /(N I R+S W I R 2)
$$

The difference between the NBR indicators $\triangle \mathrm{NBR}=\mathrm{NBR} 2013-\mathrm{NBR} 2017$ is also used, and the result can be employed as an indication of the areas that have been most damaged, to identify them and take the necessary measures. High values of $\triangle$ NBR's indicate areas with high damage, while negative values may indicate areas with possibly increased vegetation followed by a fire. Sampling areas with high NBR have been detected and verified using higher resolution images via Google Earth Pro.

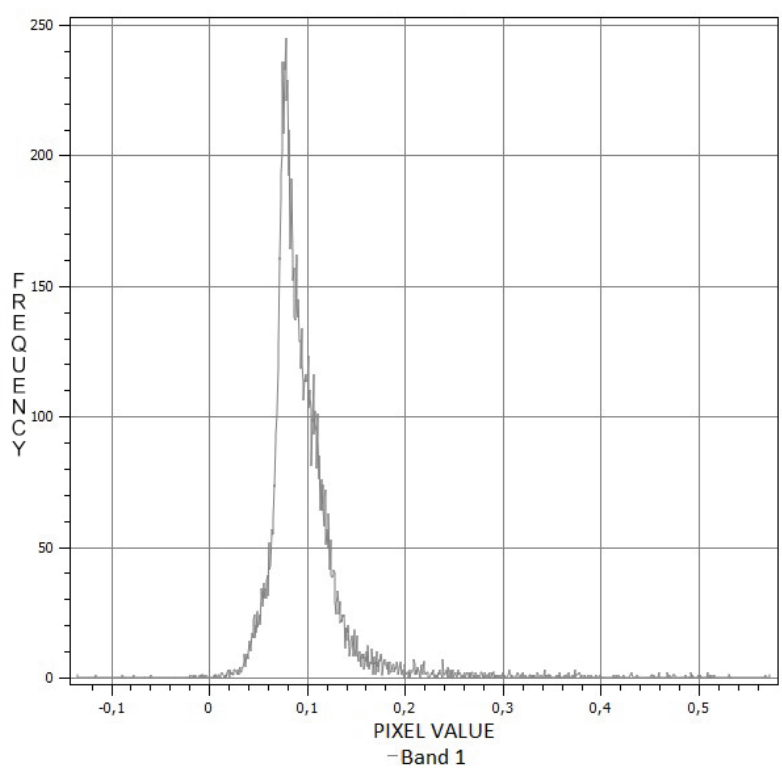

Figure 2. Histogram NDVI for 2017. 


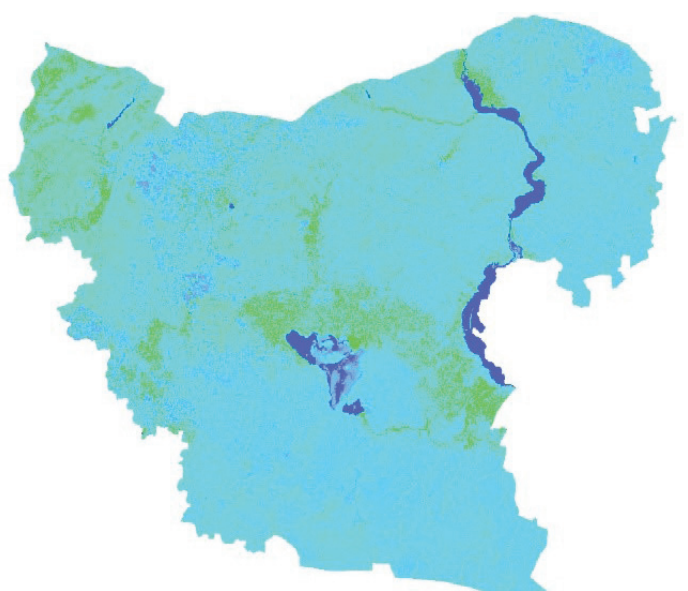

Figure 3. NDVI October 2013.

\section{Results}

\section{Satellite Sensing - Processing of satellite data and indicators.}

\section{a) Normalised Difference Vegetation Index, NDVI.}

The histograms of the produced NDVI image for the year 2013 and year 2017 are shown in Figure 1 and Figure 2, respectively. The NDVI indices created for the year 2013 and 2017, are shown in Figure 3 and Figure 4, respectively. The reference month for both years is October. The bright green areas are the most photosynthetically active. We note that for the year 2013, these areas are located in the north-western part of the government, on the east bank of Euphrates river, in the north-eastern part of the region and in a small part in the west. But most of it is in

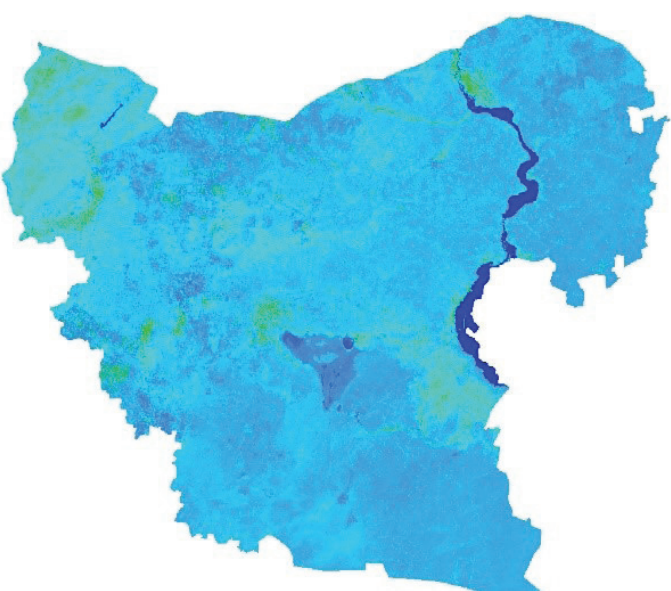

Figure 4. NDVI October 2017.

the area between Al-Assad and Jabbul lakes. According to the histogram of the produced NDVI image for the year 2013 (Figure 1), the minimum and maximum values define the interval from -0.36 to 0.61 , with an average value of 0.10 and a standard deviation of 0.05 . This means that the majority of pixel values range from 0.05 to 0.15 .

In October 2017 (Figure 4), it was found that areas with healthy vegetation were drastically reduced. They were located in the same areas as in October 2013 but occupy smaller areas. Particularly, in the area between Al-Assad and Jabbul lakes, there is no longer any area with healthy vegetation, except for a small section northeast of lake Jabbul. From the NVDI histogram for the year 2017 (Figure 2), it appears that the values of the pixels range from -0.23 to 0.61 , with an average value of 0.09 and a standard deviation of 0.04 . That is, most pixels take values from 0.05 to 0.12 .

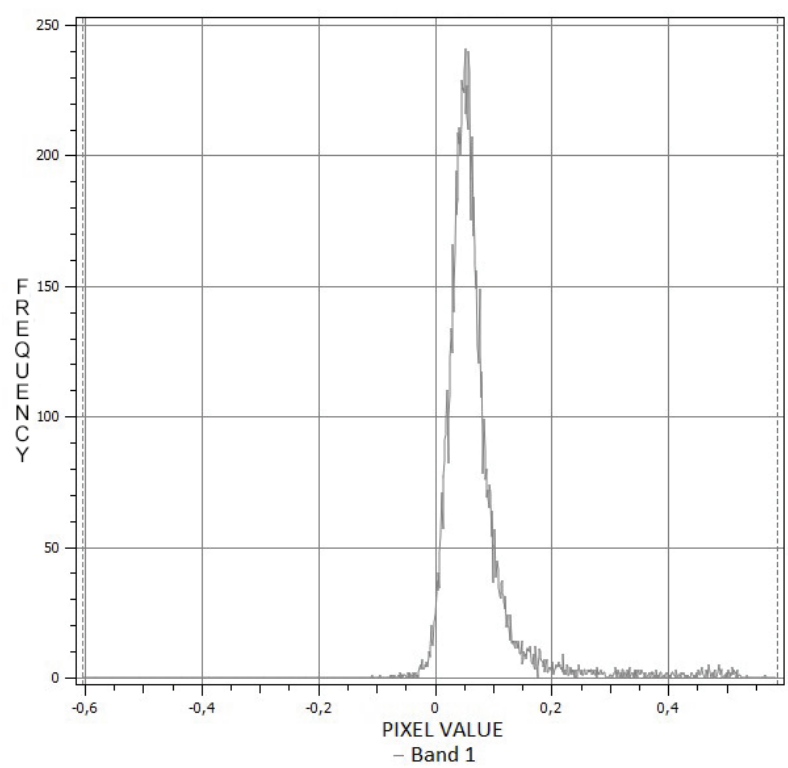

Figure 6. Histogram NBR for October 2017. 
(1) EMBnet.journal

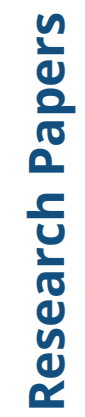

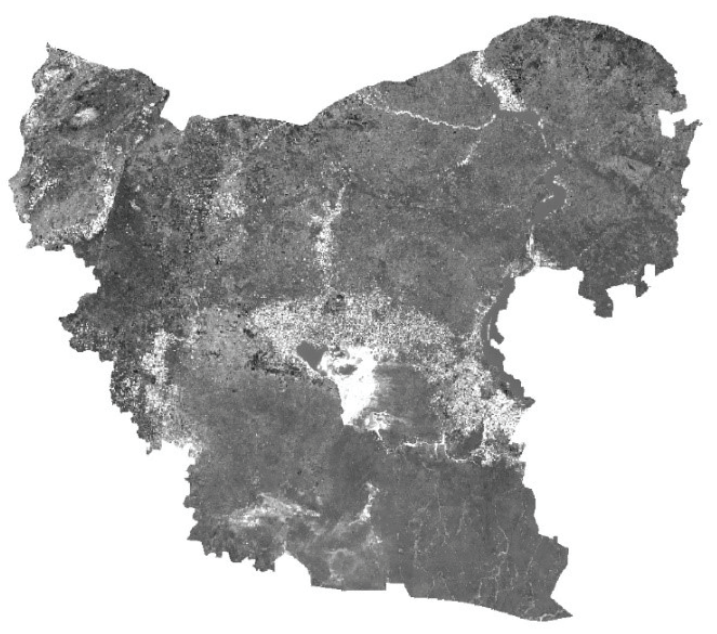

Figure 7. NBR October 2013.

b) Normalised Burn Ratio, NBR.

From the calculation of the normalised burn ratio NBR, for October 2013 (Figure 5), it appeared that the values of the pixels range from -0.74 (minimum) to 0.62 (maximum), with an average of 0.07 and standard deviation 0.06 . Thus, areas with healthy vegetation show high values and are depicted in white, while areas with burnt soil are represented by very low values and intense dark colour (Figure 7).

In October 2017 (Figure 6), the corresponding index shows a decrease in the maximum value of pixels, from 0.62 to 0.59 , while the minimum value remains almost constant, with a value of -0.73 . The average value is 0.06 and the standard deviation is 0.06 . Comparing the two images, it seems that in October 2017 healthy soils, mainly in the section between the two main lakes (Al Assad and Jabbul), are significantly reduced (Figure 8).

Additionally, the difference $\triangle \mathrm{NBR}=\mathrm{NBR} 2013$ - NBR2017 was calculated and used as a benchmark

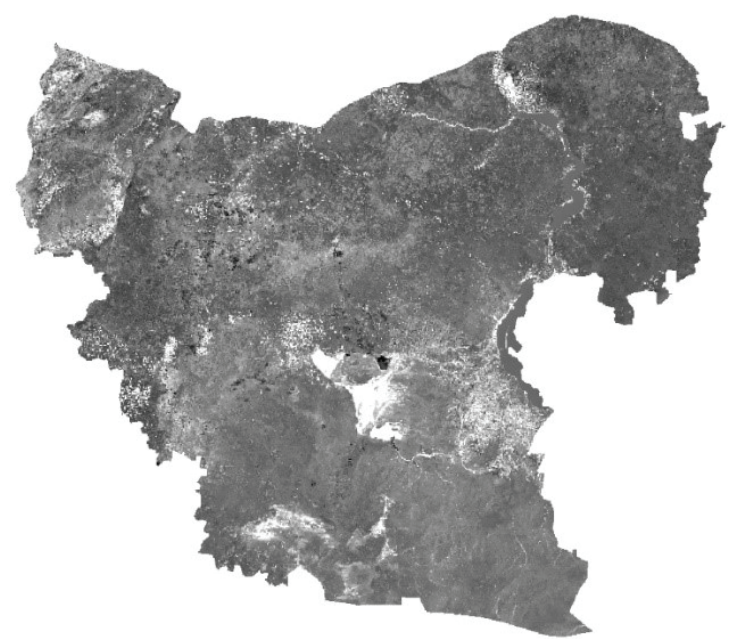

Figure 8. NBR October 2017.

between two time periods (Figure 9). With values ranging from -0.78 (minimum) to 0.89 (maximum), the average value was estimated at 0.009 with standard deviation 0.06 (Figure 10). The lighter the colour of the pixels that represent higher values, the greater the probability of the destruction in the area. From the range of most values, as shown by the standard deviation, most of the government area falls into the value range -0.1 to +0.1 . In other words, these are unburned areas.

\section{c) Colour Infrared digital image composites.}

Two digital image-composites were produced with their respective histograms for October 2013 and 2017 (Figures 11-14). For the image-composite obtained from the combination of the spectral classes 5,4,3 for October 2013, it is noted that the areas with the healthiest vegetation are located initially in the north-west, and specifically in the area of Afrin, along the homonymous river and almost for the most part of its area, and, along

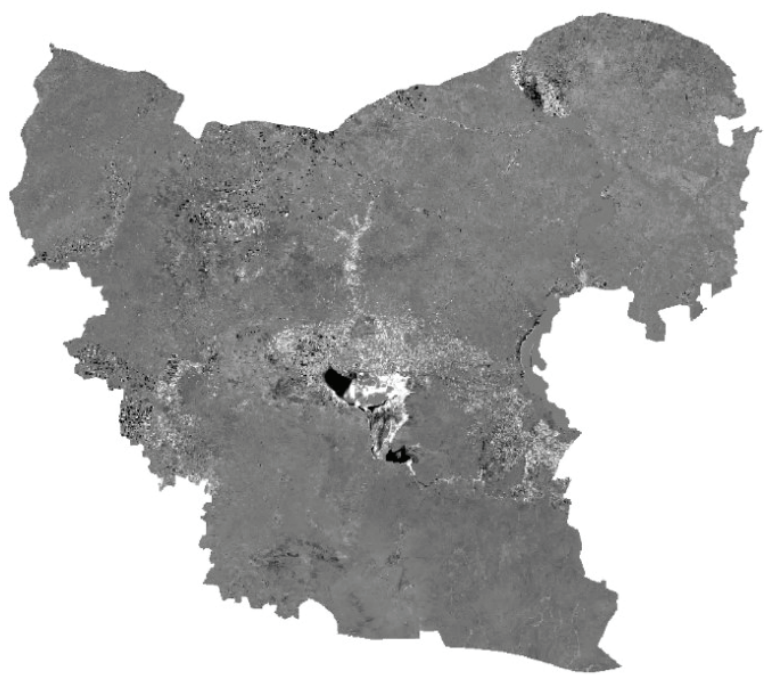

Figure 9. $\triangle N B R$.

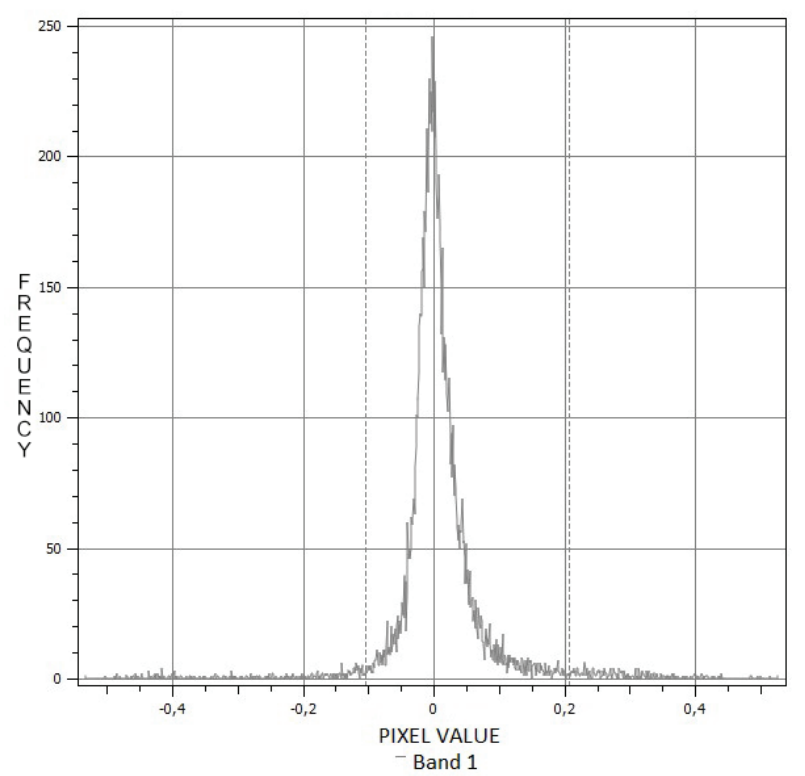

Figure 10. Histogram $\triangle \mathrm{NBR}$. 


\section{(1). EMBnet.journal}

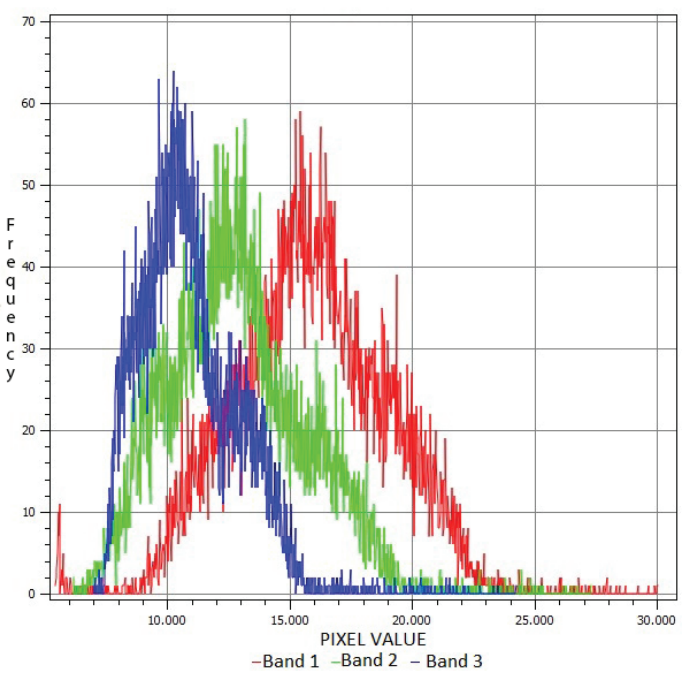

Figure 11. Histogram image-composite 2013.

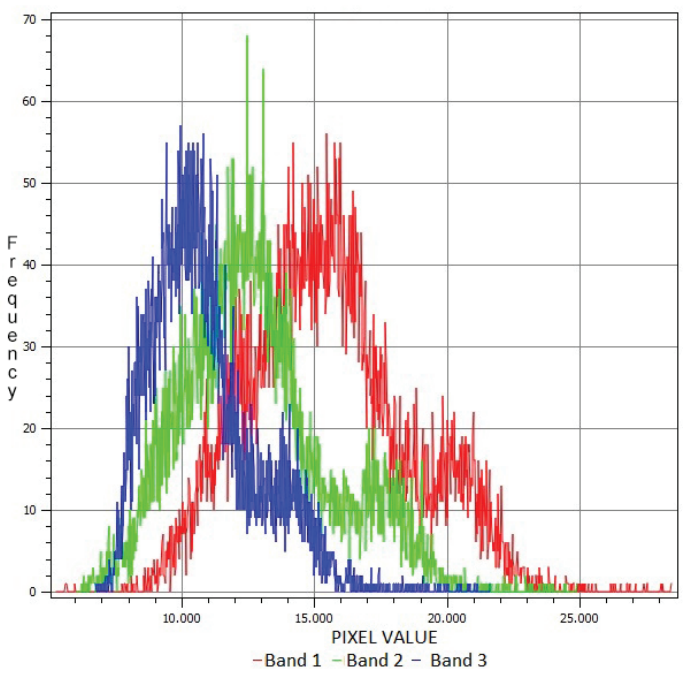

Figure 13. Histogram image composite 2017.

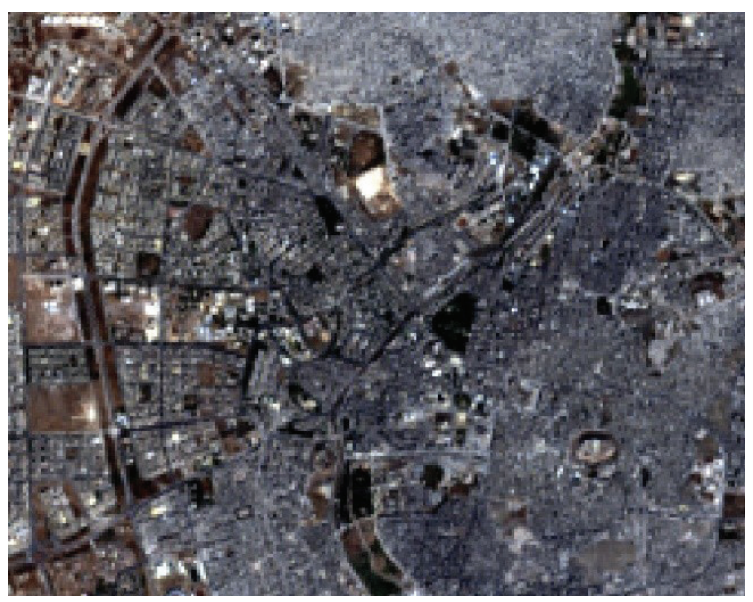

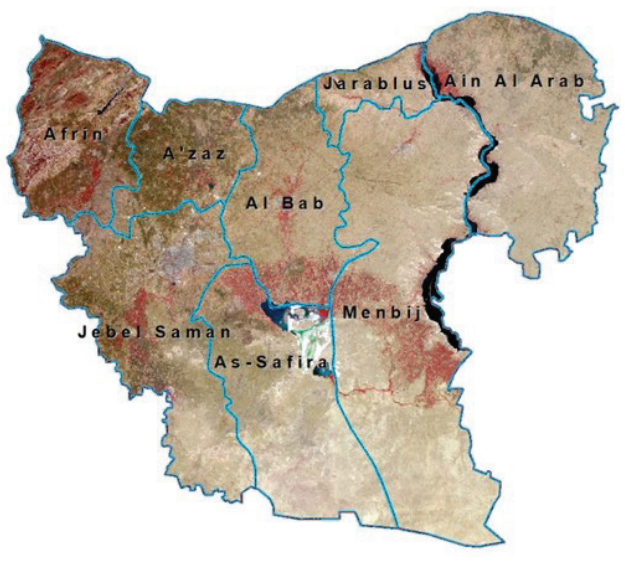

Figure 12. Image-composite 2013.

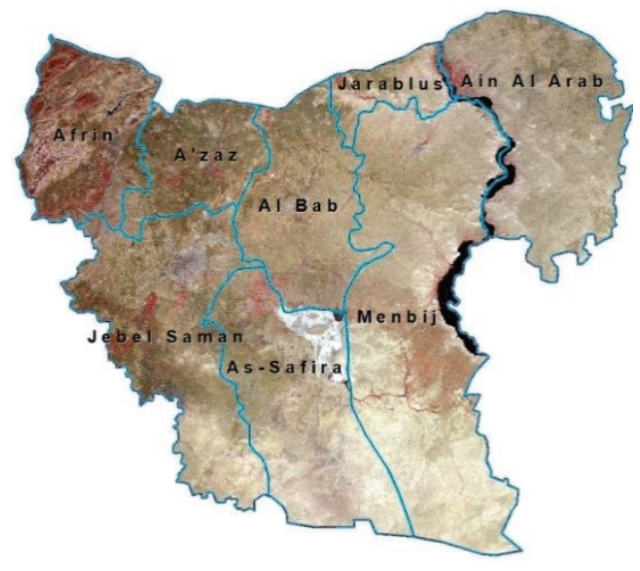

Figure 14. Image composite 2017.

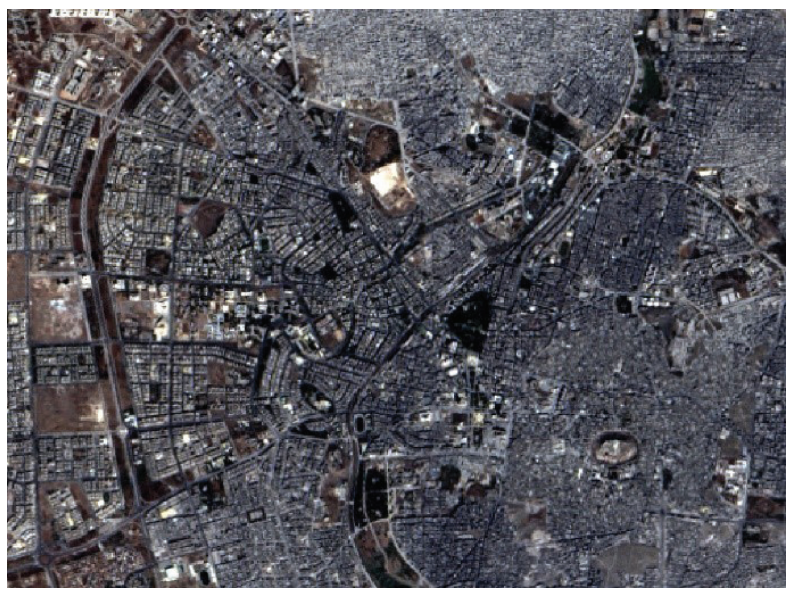

Figure 15. Part of the image pseudo-coloured composite before and after the application of the Brovey's algorithm for October 2013. 

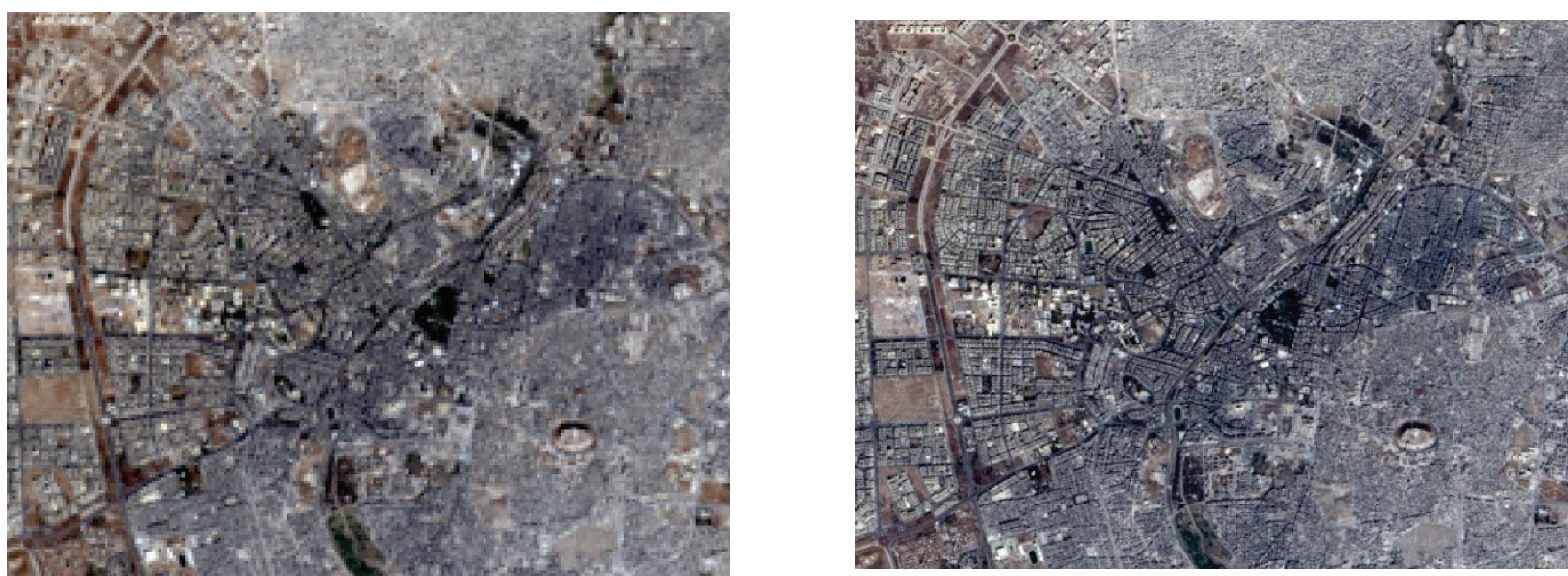

Figure 16. Part of the image pseudo-coloured composite before and after the application of the Brovey's algorithm for October 2017.

the banks of the Euphrates river in the Jarablus and Ain $\mathrm{Al}$ Arab areas, in the western part of the Jebel Saman area. The most extensive area of healthy vegetation is divided spatially between the administrative divisions of As-Safira, Al Bab and Menbij and is located in the eastern part of the government from the natural border of the Euphrates up to lake Jabbul.

In the Aleppo governorates' image-composite for October 2017, the areas of healthy vegetation appear to be significantly reduced in the eastern part of the government. Especially in the areas of Al Bab and Menbij, the reduction of healthy vegetation is extended. In the Afrin region, on the other hand, healthy vegetation is almost constant at both times.

\section{d) Pseudo-coloured image-composites.}

The image pseudo-coloured composite was produced using Landsat8's 4,3,2 spectral bands and was cut to the administrative boundaries of the city of Aleppo. The pan-sharpening process was then selected.

In the 2017 pseudo-coloured composite image, after the application of Brovey's algorithm, the areas that stand out with intense grey are the ones with the least damages
(Figure 16). On the contrary, areas of light colour tonality are the ones that have suffered extensive damage from the attacks. Such sharp differences were not detected in the city's pseudo-coloured image for October 2013 (Figure 15).

Analysing the data concerning the destroyed buildings in the neighbourhoods of Aleppo city, collected by UNOSAT for July 2015, it emerged that in all 115 areas where damage was recorded, $53.91 \%$ of them suffered damages of their building structures up to $20 \%$, while $28.70 \%$ reached $20 \% \sim 40 \%$ damage of their building structures. At a rate of $17.39 \%$, more than $40 \%$ of their building structures were destroyed. The Al Aqabeh, Tal Az-Zarazi (Al-Ameria) and Handarat regions recorded the largest disasters with $65.61 \%, 61.42 \%$ and $61.20 \%$, respectively.

\section{e) Classification of digital image composites.}

The two image-composites of spectral bands 6,5,2 (short infrared, near-infrared and blue), for October 2013 (Figure 17) and 2017 (Figure 18), were classified into six classes, due to the ability to separate active crops that appear with bright green colour. The rest of the classes

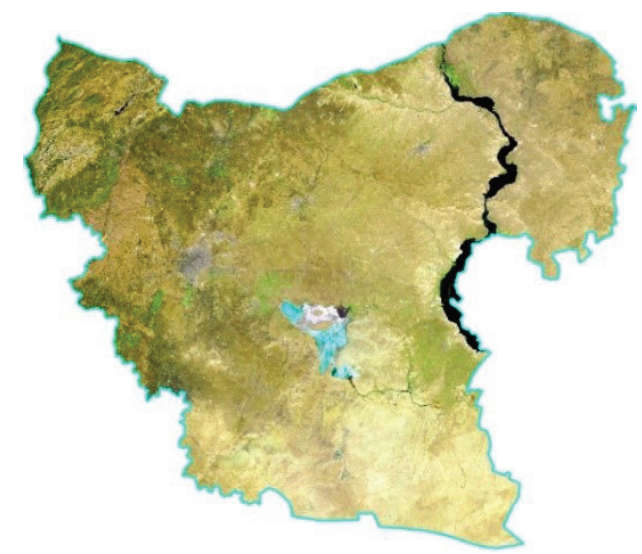

Figure 17. Image composite 6,5,2 (2013).

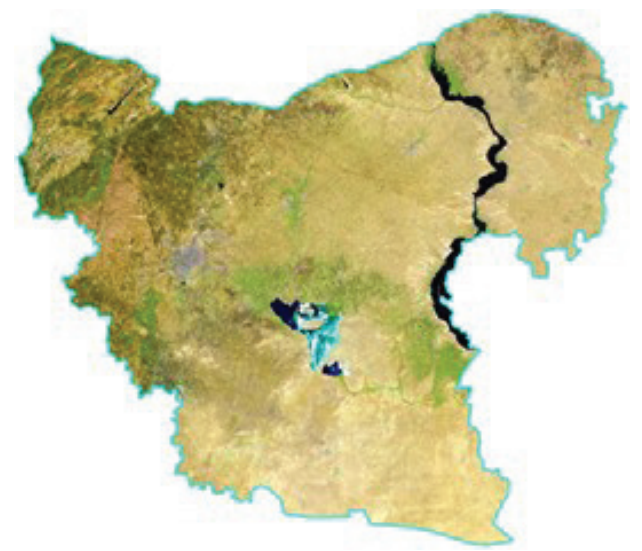

Figure 18. Image composite 6,5,2 (2017). 
Table 2. Reference points to evaluate accuracy of classification.

\begin{tabular}{lcc} 
& $\mathbf{2 0 1 3}$ & $\mathbf{2 0 1 7}$ \\
\hline Bare soil & 107 & 124 \\
\hline Water bodies & 11 & 11 \\
\hline Urban areas & 13 & 13 \\
\hline Active cropland & 37 & 14 \\
\hline Inactive cropland & 76 & 83 \\
\hline Small trees & 6 & 5
\end{tabular}

created are also adequately separated since water bodies appear in blue, urban areas in grey, and bare soil in light shades of brown.

From the classified images for 2013 (Figure 17) and 2017 (Figure 18), it is demonstrated that there has been a reduction in active crops in 2017, as well as an increase in areas classified as bare soil. The small trees class, in the north-eastern part of the governorate is declining in 2017. Easily distinguishable are the area's dominant water bodies, the Euphrates river, lake Al Assad and Jabbul, as well as the lake Maydanki. However, there have been alterations noticed in the size of lake Jabbul in 2017. The urban network of Aleppo is quite visible in both classified images.

Both images were examined for the accuracy of their classification. 250 reference points were used, randomly selected, and placed in one of the six classes based on observations via digital images of high spatial resolution available in Google Earth Pro. These points due to their random selection are not evenly distributed in each class (Table 2). Most of the points belong to the classes of bare soil and inactive crops, while the minority belongs to the class of small trees. There is also a decrease in the reference points of the class of active crops in 2017 compared to 2013.

The results of the evaluation of the accuracy of the two classified images (Figure 19 and 20) are presented in Table 3 for October 2013 and Table 4 for October 2017.

There is an increase in bare soil areas and areas with inactive cropland. The area covered by urban areas remains the same at both times. Reduction of the area is presented in the classes of active crops, waterbodies, and small trees. Particularly in active crops, the reduction in area is $61.64 \%$, as shown by the values of the area of the category from the classification accuracy classification tables. The confidence interval column shows the degree of uncertainty of the sample, i.e., for each class, and shows the extent to which it is considered to have been classified in the wrong class. Particularly high uncertainty is found in the classification of tree cover in both classified images.

\section{Discussion}

Most of the conflicts, especially in the case of Syria, have resulted in large population immigration phenomena, changing existing land use, and creating new dynamics in natural ecosystems. The environmental consequences of war are not limited to terrestrial ecosystems, but also to aquatic ecosystems as they are as intense as the contamination of both surface and groundwaters (Biswas, 2001). In addition, the effects on the atmosphere and their possible dispersion depend on the atmospheric and weather conditions of each region.

The use of satellite sensing techniques with the help of G.I.S. is a useful tool while trying to record the environmental impacts of war. By processing and analysing them, researchers are able to collect useful data for war zones that would be otherwise difficult and/ or impossible to access. This makes it possible to assess and evaluate the situation and establish an immediate intervention. The analysis of satellite images gives the advantage of the spatial-temporal study of the war zones with the use of indicators, such as the NDVI index, which provides information on vegetation status. The use of the NDVI index has been shown in many cases to be related to armed conflicts with changes in vegetation, whether it was due to direct use, the use of weapons, or indirectly from the abandonment of rural areas and/or the use of forest areas for timber. (Witmer, 2008; Brown, 2010; Witmer and O'Loughlin, 2011; Mitri et al., 2014; Muller et al., 2016).

In the present study, the use of the normalised vegetation index (NDVI) showed that there is a decrease

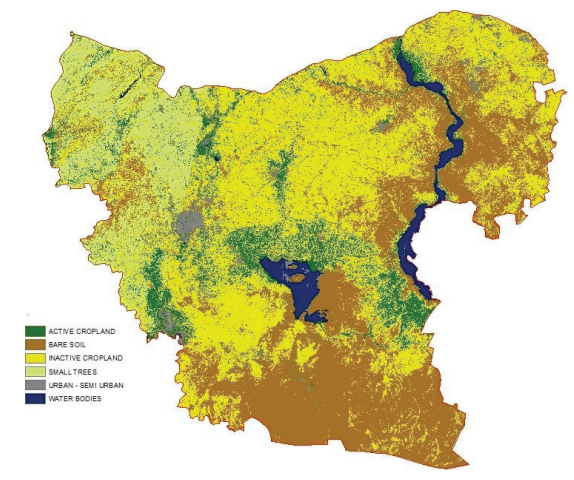

Figure 19. Classified image October 2013.
Table 3. Integrated classification accuracy scoreboard -2013 .

\begin{tabular}{|c|c|c|c|c|c|}
\hline Classes & Area (ha) & $\pm 95 \%$ CI & $\begin{array}{c}\text { Observer } \\
\text { accuracy } \\
(\%)\end{array}$ & $\begin{array}{c}\text { Analyst } \\
\text { accuracy } \\
(\%)\end{array}$ & $\begin{array}{c}\text { Total } \\
\text { accuracy } \\
(\%)\end{array}$ \\
\hline Bare soil & $838,726.80$ & $104,424.86$ & 81.2 & 61.7 & \\
\hline Water bodies & $53,575.17$ & $9,546.12$ & 91.7 & 100 & \\
\hline Urban areas & $100,296.75$ & $49,821.78$ & 46.2 & 41.9 & \\
\hline $\begin{array}{l}\text { Active crop- } \\
\text { land }\end{array}$ & $303,022.65$ & $84,196.22$ & 47.8 & 26.7 & 56.9 \\
\hline $\begin{array}{l}\text { Inactive crop- } \\
\text { land }\end{array}$ & $645,680.95$ & $108,994.40$ & 52.1 & 67.9 & \\
\hline Small trees & $46,892.90$ & $37,155.03$ & 0 & 0 & \\
\hline
\end{tabular}




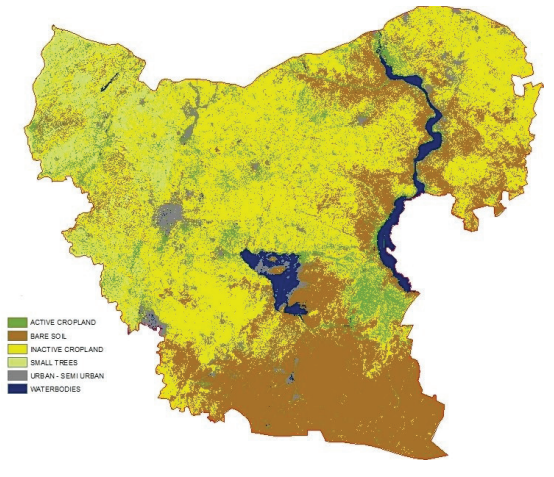

Figure 20. Classified image October 2017.
Table 4. Integrated classification accuracy scoreboard -2017.

\begin{tabular}{|c|c|c|c|c|c|}
\hline Classes & Area (ha) & $\pm 95 \% \mathrm{CI}$ & $\begin{array}{c}\text { Observer } \\
\text { accuracy } \\
(\%)\end{array}$ & $\begin{array}{c}\text { Analyst } \\
\text { accuracy } \\
(\%)\end{array}$ & $\begin{array}{c}\text { Total } \\
\text { accuracy } \\
(\%)\end{array}$ \\
\hline Bare soil & $954,329.71$ & $107,468.43$ & 85.5 & 51.3 & \multirow{6}{*}{54.8} \\
\hline Water bodies & $60,229.16$ & $24,581.03$ & 81.8 & 75.2 & \\
\hline Urban areas & $100,894.70$ & $52,607.54$ & 27.8 & 34.6 & \\
\hline $\begin{array}{l}\text { Active crop- } \\
\text { land }\end{array}$ & $116,233.69$ & $55,853.37$ & 27.8 & 34.1 & \\
\hline $\begin{array}{l}\text { Inactive crop- } \\
\text { land }\end{array}$ & $717,530.37$ & $111,922.42$ & 49.5 & 66.9 & \\
\hline Small trees & $38,977.58$ & $34,054.30$ & 0 & 0 & \\
\hline
\end{tabular}

in healthy vegetation between 2013 and 2017, mainly in the riverine areas of the Euphrates, in the north-western area of the government, and especially in the rural area southeast of Aleppo, in Al-Assad and Jabbul lakes. The vegetation for October 2017 remains healthy in the northeast of lake Jabbul. The same conclusion emerges from the interpretation of the colour-infrared imagecomposites created. The NBR's burn rate index, as well as the $\triangle \mathrm{NBR}$ difference between the two indices for October 2013 and 2017, identified some burned areas but had to be confirmed by high-resolution images, and/ or observers in the area. Even if it may not be highly suitable for areas with sparse vegetation, such as the governorate of Aleppo, it is particularly useful in areas with intense vegetation. Still, its use is recommended as long as there is a way to strongly identify the results.

The pseudo-coloured image-composites for the city of Aleppo were also the first indication of the areas damaged. With the analysis of statistical data and their representation, along with the help of geographic information systems, the indications of the image-composites were confirmed. Correspondingly, the classified digital images also showed a significant decrease in cultivated areas with an increase in abandoned agricultural areas and areas of intense soil erosion. Although the overall accuracy of the classified images was relatively low, statistics on the Aleppo government confirm these changes.

In conclusion, the consequences of a war on the environment are multidimensional, either direct or indirect, affecting natural ecosystems in ways that are often irreversible. The environmental impact of war creates social and economic consequences, which further degrade the environment by showing the need to consider the effects in a more comprehensive approach, while the synergy of the already degraded environment

\section{Key Points}

- War has great environmental impacts that create social and economic consequences.

- Environmental impacts are identified using satellite-derived images.

- Geographic information systems can be a useful to remotely analyse war zones where physical observations are impossible. in the scale of the humanitarian crisis must not be underestimated.

\section{References}

1. Ajmi DA and Ud din S (2009) Remote Sensing: Fundamentals, Types and Monitoring Applications of Environmental Consequences of War. In: KassimTA and BarcelóD (eds) Environmental Consequences of War and Aftermath. The Handbook of Environmental Chemistry. Springer, Berlin, Heidelberg, Berlin, Heidelberg,pp. 41-124

2. Biswas AK (2000) Scientific assessment of the long-term environmental consequences of war. In: BruchCE and AustinJE (eds) The Environmental Consequences of War: Legal, Economic, and Scientific Perspectives. Cambridge University Press, Cambridge, Cambridge,pp. 303-315

3. Brown IA (2010) Assessing eco-scarcity as a cause of the outbreak of conflict in Darfur: a remote sensing approach. International Journal of Remote Sensing 31 (10), 2513-2520. http://dx.doi. org/10.1080/01431161003674592

4. Central Bureau Of Statistics (CBS) (2004) Statiscal Abstarctial 2004. http://www.cbssyr.sy/yearbook/2004/syr2004En.htm (Accessed 20 March 2018).

5. Central Bureau Of Statistics Syria (CBS) (2003 2017). Statistical Abstract. http://www.cbssyr.sy/index-EN.htm (Accessed 20 March 2018).

6. Clark B and Jorgenson AK (2012) The Treadmill of Destruction and the Environmental Impacts of Militaries. Sociology Compass 6 (7), 557-569. http://dx.doi.org/https://doi.org/10.1111/j.17519020.2012.00474.x

7. Erian W (2011) Drought Vulnerability in the Arab Region; Case Study- Drought in Syria: Ten Years of Scarce Water (2000 - 2010), Damascus: Arab Center for the Studies of Arid Zones and Dry Lands (ASCAD) \& UN secretariat of the International Strategy for Disaster Reduction, Regional Office for Arab States (ISDR).

8. ESRI (2011) How Maximum Likelihood Classification works. http://help.arcgis.com/en/arcgisdesktop/10.0/help/ index.html\#/How_Maximum_Likelihood_Classification works/009z000000q9000000/ (Accessed 10 March 2018).

9. Food And Agriculture Organization Of The United Nations (FAO) (2016). FAO/WFP Crop and Food Security Assessment Mission To The Syrian Arab Republic, Rome: FAO.

10. Gaynor KM, Fiorella KJ, Gregory GH, Kurz DJ, Seto KL, et al. (2016) War and wildlife: linking armed conflict to conservation. Frontiers in Ecology and the Environment 14 (10), 533-542. http://dx.doi.org/https://doi.org/10.1002/fee.1433

11. Khordagui $\mathrm{H}$ and Al-Ajmi D (1993) Environmental impact of the Gulf War: An integrated preliminary assessment. Environmental Management 17 (4), 557-562. http://dx.doi.org/10.1007/! BF02394670 
12. Machlis GE and Hanson T (2008) Warfare Ecology. BioScience 58 (8), 729-736. http://dx.doi.org/10.1641/B580809

13. MapAction; Assessment Capacities Project (ACAPS) (2013) Aleppo - Governorate profile March 2013. https://reliefweb. int/report/syrian-arab-republic/aleppo-governorate-profilemarch-2013 (Accessed 21 April 2018).

14. Misak R, Al-Ajmi D, and Al-Enezi A (2009) War-Induced Soil Degradation, Depletion, and Destruction (The Case of Ground Fortifications in the Terrestrial Environment of Kuwait). In KassimTA and BarcelóD (eds) Environmental Consequences of War and Aftermath. The Handbook of Environmental Chemistry. Springer, Berlin, Heidelberg, Berlin, Heidelberg, pp. 125-139

15. Mitri G, Nader M, Van der Molen I, and Lovett J (2014) Evaluating exposure to land degradation in association with repetitive armed conflicts in North Lebanon using multi-temporal satellite data. Environ Monit Assess 186 (11), 7655-7672. http://dx.doi. org/10.1007/s10661-014-3957-5

16. Müller MF, Yoon J, Gorelick SM, Avisse N and Tilmant A (2016) Impact of the Syrian refugee crisis on land use and transboundary freshwater resources. PNAS 113 (52), 14932-14937. http:!/! dx.doi.org/10.1073/pnas.1614342113

17. Nasser R, Mehchy Z and Ismail CA (2013) Socieconomic Roots and Impact of the Syrian Crisis, Damascus: The Syrian Center for Policy Research.

18. Office for the Coordination of Humanitarian Affairs (OCHA) (2018) Humanitarian Response Plan: January - December 2018 https://www.humanitarianresponse.info/en/operations/wholeof-syria/document/syrian-arab-republic-2018-humanitarianresponse-plan-january (Accessed 26 November 2019).

19. Pettersson T and Eck K (2018) Organized violence, 1989-2017. Journal of Peace Research 55 (4), 535-547. http://dx.doi. org $/ 10.1177 / 0022343318784101$

20. Saadé-Sbeih M, Zwahlen F, Haj Asaad A, Gonzalez R, and Jaubert $R$ (2016) Post conflict water management: learning from the past for recovery planning in the Orontes River basin. In: Proceedings of the International Association of Hydrological Sciences. Copernicus GmbH, Vol 374, pp. 17-21

21. Syria Needs Analysis Project (SNAP) (2013) ALEPPO Governorate profile. https://reliefweb.int/report/syrian-arabrepublic/aleppo-governorate-profile-march-2013 (Accessed 20 December 2019).
22. Syrian Center for Policy Research (SCPR) (2016) Forced Dispression. A Demographic Report on Human Status in Syria, Damascus: The Syrian Center for Policy Research (SCPR).

23. The World Bank (2017) SYRIA DAMAGE ASSESSMENT of selected cities Aleppo, Hama, Idlib, Washington DC: The World Bank Group.

24. The World Bank (2017) THE TOLL OF WAR, Washington, DC: World Bank Group.

25. U.S.Geological Survey (USGS) (2013) LC81730352013274LGN01. https://earthexplorer.usgs.gov/ (Accessed 10 November 2019).

26. U.S. Geological Survey (USGS) (2013) LC81740352013281LGN01. https://earthexplorer.usgs.gov/ (Accessed 11 December 2019).

27. U.S. Geological Survey (USGS) (2016) LANDSAT 8 (L8) DATA USERS HANDBOOK. https://landsat.usgs.gov/sites/default/ files/documents/Landsat8DataUsersHandbook.pdf (Accessed 12 December 2019).

28. U.S. Geological Survey (USGS) (2017) Landsat Surface Reflectance-Derived Reflectance Spectral Indices. https://landsat. usgs.gov/sites/default/files/documents/si_product_guide.pdf (Accessed 12 December 2019).

29. U.S.Geological Survey (USGS) (2017) LC81730352017285LGN01. https://earthexplorer.usgs.gov/ (Accessed 20 December 2019).

30. U.S.Geological Survey (USGS) (2017) LC81740352017292LGN00. https://earthexplorer.usgs.gov/ (Accessed 12 December 2019).

31. Uppsala Conflict Data Program (2018) Uppsala Conflict Data Program - Department of Peace and Conflict Research. http:// ucdp.uu.se/\#country/652 (Accessed 12 November 2019).

32. Witmer FDW and O'Loughlin J (2009) Satellite Data Methods and Application in the Evaluation of War Outcomes: Abandoned Agricultural Land in Bosnia-Herzegovina After the 1992-1995 Conflict. Annals of the Association of American Geographers 99 (5), 1033-1044. http://dx.doi.org/101080/00045600903260697.

33. Witmer FDW (2008) Detecting war-induced abandoned agricultural land in northeast Bosnia using multispectral, multitemporal Landsat TM imagery. International Journal of Remote Sensing 29 (13), 3805-3831. http://dx.doi. org $/ 10.1080 / 01431160801891879$

34. Zwijnenburg W, Pas KT (2015) Amidst the debris...A desktop study on the environmental and public health impact of Syria's conflict, Utrecht: PAX. 